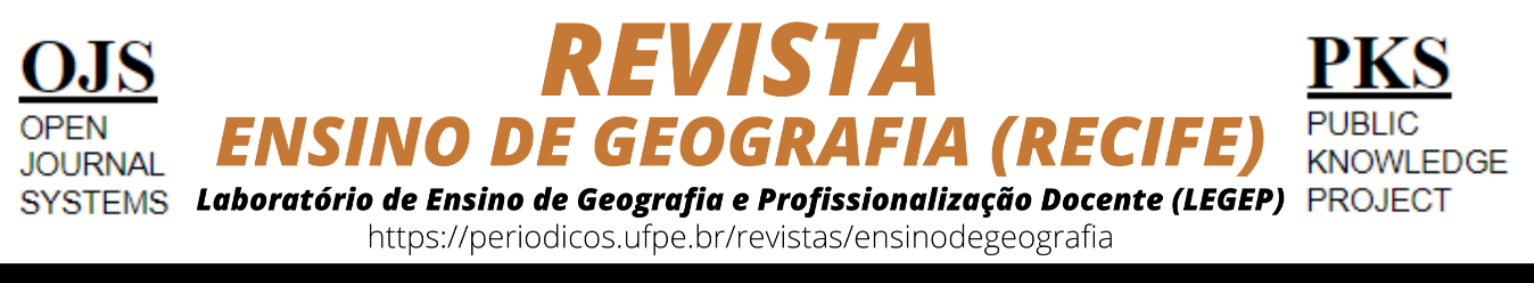

\title{
A LEI 13.415/2017 E O LUGAR DA GEOGRAFIA ESCOLAR NA ESTRUTURA CURRICULAR DO ENSINO MÉDIO
}

\author{
Paulo Sérgio Cunha Farias ${ }^{1}$
}

IProfessor do Centro de Humanidades da Universidade Federal de Campina Grande (UFCG). E-mail: pscfarias@bol.com.br-ORCID iD: http://orcid.org/0000-0002-4643-2306;

Artigo recebido em 21/04/2020 e aceito em 01/05/2020

\begin{abstract}
RESUMO
Este estudo objetiva analisar os impactos da Lei 13.415/2017, que reformulou a Lei 9.394/1996 e instaurou o chamado "Novo Ensino Médio". Atenta para a questão da estrutura curricular proposta por ela para essa etapa do ensino e como nessa estrutura a Geografia aparece contemplada. A análise toma a própria Lei como instrumento de investigação empírica, constituindo-se a partir de uma abordagem qualitativa e documental. No campo das ideias, fundamenta-se nas teorias críticas da Educação e da Geografia. Conclui-se que a reforma curricular estabelecida pela Lei 13.415/2017, ao tornar a Geografia Escolar matéria optativa no currículo do Ensino Médio, poderá empobrecer a formação dos jovens brasileiros das classes populares, interditando as suas possibilidades de fazer a leitura crítica do mundo através do espaço geográfico, o que limitará a sua ação política em seus contextos espaciais. No geral, a desobrigação curricular da Geografia é parte do caráter "minimalista, dual e desigual" que caracteriza essa reforma educacional. Por outro lado, expressa as tendências pedagógicas pragmáticas coincidentes com os postulados neoliberais vigentes atualmente na educação nacional.
\end{abstract}

Palavras-chave: Lei 13.415. Currículo. Ensino Médio. Geografia Escolar.

\section{THE BRAZILIAN LAW 13.415 / 2017 AND THE PLACE OF HIGH SCHOOL GEOGRAPHY IN THE CURRICULUM STRUCTURE}

\begin{abstract}
This study aims to analyze the impacts of the the Law 13. 415/2017, which reformulated the Law 9. 394/1996 and introduced the so-called Novo Ensino Médio -"New High School". Looking at the issue of the curricular structure proposed by the Law for this stage of teaching and with this structure, Geography appears contemplated. This analysis takes the law itself as an instrument of empirical investigation, constituting in a qualitative and documental approach. In the world of ideas, it is based on the critical theories of education and geography. We concluded that the curricular reform established by the Law 13. 415/2017 making the School Geography an optional subject in the High School curriculum could impoverish the young Brazilians formation, from the popular classes, interdicting their possibilities of critical reading of the world through landscape which, will limit the political actions in their territorial contexts. In general, the curricular dispensation of Geography it is part of the "minimalist, dual and unequal" character which that characterizes this educational reform. On the other hand, it shows the pragmatic pedagogical tendencies that coincide with the current neoliberal postulates in national education.
\end{abstract}


Keywords: Law 13,415. Curriculum. High school. School Geography.

\title{
LEY 13.415 / 2017 Y EL LUGAR DE LA GEOGRAFÍA ESCOLAR EN LA ESTRUCTURA CURRICULAR DE LA ESCUELA SECUNDARIA
}

\begin{abstract}
RESUMO
Este estudio tiene como objetivo analizar los impactos de la Ley 13.415 / 2017, que reformuló la Ley 9.394 / 1996 y estableció el denominado "Nuevo Bachillerato". Atento a la cuestión de la estructura curricular propuesta por ella para esta etapa de la docencia y cómo aparece la Geografía en esta estructura. El análisis toma la propia Ley como instrumento de investigación empírica, constituyéndose desde un enfoque cualitativo y documental. En el campo de las ideas, se basa en teorías críticas de la Educación y la Geografía. Se concluye que la reforma curricular establecida por la Ley 13.415 / 2017, al hacer de la Geografía Escolar una asignatura optativa en el currículo de Bachillerato, puede empobrecer la formación de los jóvenes brasileños de las clases populares, restringiendo sus posibilidades de hacer una lectura crítica del mundo a través de espacio geográfico, que limitará su acción política en sus contextos espaciales. En general, la liberación curricular de Geografía forma parte del carácter "minimalista, dual y desigual" que caracteriza esta reforma educativa. Por otro lado, expresa las tendencias pedagógicas pragmáticas que coinciden con los postulados neoliberales actualmente vigentes en la educación nacional.

Palavras clave: Ley 13.415. Plan de estudios. Escuela secundaria. Geografía escolar.
\end{abstract}

\section{INTRODUÇÃO}

Pensar os rumos do ensino da Geografia nos sistemas escolares brasileiros, especialmente no que toca aos que ofertam o Ensino Médio, obriga-nos a refletir sobre o projeto nacional para a educação posto para a sociedade depois do golpe parlamentar/judiciário/midiático de 2016.

Portanto, pensar a educação e o lugar da Geografia como parte dela exige um esforço para se enxergar os processos econômicos, políticos, culturais e sociais vigentes que buscam lhes definir, por meio de legislações, currículos, materiais pedagógicos, profissionalização do magistério, políticas salarias para os professores, estrutura das escolas etc. No espaço dessa reflexão atentaremos para a Lei 13.415/2017, que reformulou a Lei 9. 394/1996, bem como os seus impactos na estrutura do currículo para o Ensino Médio e como se posiciona a Geografia nas letras dessa lei.

Entendemos que tanto o que se espera da educação (seus fins e objetivos) quanto o que se define como será essa educação (políticas curriculares) são historicamente determinados e resultam de um jogo em que interesses estão em disputas. Nesse caso, a Lei 13.415/2017 se constitui como um dos componentes do pacote de mudanças conservadoras impostas pelo governo de Michel Temer à sociedade brasileira, especialmente à classe trabalhadora. Esse pacote recoloca o Brasil nos trilhos ortodoxos do neoliberalismo e, consequentemente, da globalização do capitalismo, de maneira subalterna e periférica, e, como parte dele, a educação é realinhada aos ditames do mercado, cujo exemplo é o chamado novo Ensino Médio instaurado com essa lei. 
Assim sendo, este estudo objetiva analisar alguns aspectos gerais da Lei 13.415/2017, notadamente àqueles que incidem diretamente sobre a estrutura curricular do Ensino Médio. Procura revelar como, na letra dessa lei, a Geografia aparece contemplada. Busca, também, compreender essa reforma no atual contexto de aprofundamento das doutrinas neoliberais, nas esferas política, econômica, social e cultural pelo estado brasileiro, e como elas impactam a educação.

Na procura por alcançar os objetivos anunciados, estruturamos o texto da seguinte maneira: primeiramente, esboçaremos o conteúdo da Lei 13.415/2017; posteriormente, explicitaremos o seu caráter de legislação como parte do projeto neoliberal para a educação nacional e, finalmente, buscaremos situar o lugar da Geografia no Ensino Médio, conforme dita a referida lei, bem como os impactos dessa posição para a formação dos jovens da classe trabalhadora brasileira.

\section{NA LETRA DA LEI O ENSINO MÉDIO: A LEI 13.415/2017}

Embora fosse uma necessidade e já estivesse programada para acontecer, a reforma do Ensino Médio se concretizou em um contexto de quebra do pacto político que permitiu a ascensão e os governos do Partido dos Trabalhadores por 13 anos. Essa ruptura, orquestrada pelas elites e fortemente apoiada por segmentos da classe média e da classe trabalhadora, deu-se em um momento de queda dos preços das commodities brasileiras no mercado internacional, impulsionada pela retração da demanda chinesa, o que provocou desequilíbrios na balança comercial, baixo crescimento econômico e a contração de investimentos públicos. Dentro dessa conjuntura, para manter seus ganhos e privilégios, as elites brasileiras, fortemente representadas no legislativo, no judiciário e nos veículos de comunicação de massa, iniciaram um ataque ao modelo neodesenvolvimentista de Estado dos 13 anos anteriores, que combinou doutrinas neoliberais com investimentos no campo social. O ápice desse ataque foi o impeachment fraudulento da presidente reeleita em 2014, após quase dois anos de boicotes que inviabilizaram a sua governabilidade, por parte do judiciário, legislativo e do seu vice-presidente, esse representante das elites no pacto que houvera permitido a governabilidade de um partido de centro-esquerda. Com a ascensão do vice-presidente ao poder inicia-se um plano de restruturação do papel do Estado em moldes mais profundos do neoliberalismo. Entre os setores que deveriam ser reformados para atender aos imperativos do mercado estava à educação. Entre os conteúdos das reformas educacionais, estabeleceu-se, no plano das normas, a Lei 13.415/2017, que instaurou o chamado Novo Ensino Médio. 
Como é corriqueiro às elites brasileiras, toda reforma de cunho conservador é divulgada para a população camuflando o seu real teor e amparada em argumentos falsos ou frágeis. No caso da reforma do Ensino Médio, não foi diferente. Após a sua anunciação, em setembro de 2016, Frigotto (2016a) esclareceu que os argumentos do governo eram de que essa etapa do ensino no Brasil representava o principal desafio da educação brasileira, pois este apresentava um quadro de estagnação das matrículas e o país contava com mais de um milhão de jovens de 15 a 17 anos fora da escola. Amparava-se, também, em um dado de pesquisa da Fundação Getúlio Vargas de que 40,3\% desses jovens apresentavam a falta de interesse por essa etapa da educação. Portanto, esta se encontrava estagnada, a evasão era muito elevada e havia o desinteresse dos jovens por ela, daí a justificativa para reformá-la, com a chamada criação do "Novo Ensino Médio". Desse modo, o grupo que assumiu o MEC no pós-impeachment, utilizando-se desses argumentos como justificativa, resolveu reformar essa etapa escolar por meio de Medida Provisória. Assim sendo, em 23 de outubro de 2016, publicou a MP 746/2016, que instaurou a chamada criação do novo Ensino Médio. Segundo esse grupo, a medida considera prioritárias as necessidades individuais dos estudantes e oferece oportunidades equivalentes às ofertadas nos principais países do mundo.

Com amparo nesses argumentos, após aprovação na Câmara (dezembro de 2016) e no Senado (fevereiro de 2017), sancionado pelo presidente (em 08 de fevereiro de 2017), tudo em caráter de urgência, como, aliás, foram impostas às reformas que suprimiram os direitos dos trabalhadores no Governo Temer, no dia 17 de fevereiro de 2017, o texto final da reforma do Ensino Médio foi publicado no Diário Oficial da União como a Lei 13.415, alterando as Diretrizes e Bases da Educação Nacional. O referido texto (BRASIL, Lei 13.415, 2017) trouxe: mudanças na carga horária destinada à formação dos nossos jovens, que deverá passar das atuais 800 horas anuais (4 horas e trinta minutos diários em média) para 1.000 horas (5 horas diárias), para, progressivamente, ainda ser ampliada para 1.400 horas (7 horas diárias), o que configurará um sistema de educação integral, que deve ser estabelecido no decorrer de cinco anos; na estrutura curricular, definindo que apenas Matemática e Língua Portuguesa serão disciplinas obrigatórias nos três anos desse nível da Educação Básica (Artigo 35-A, parágrafos $3^{0}$ e $4^{0}$ ); impactos negativos na formação de alunos e prejuízos na dos professores, ao prever a aceitação de profissionais de "notório saber" no exercício do magistério de temas ou conteúdos que não são da sua formação.

As questões relativas às mudanças curriculares são as que nos preocupam mais diretamente nesse estudo, embora tenhamos consciência de que a liberação de profissionais de "notório saber", 
sem a preparação pedagógica para atuar na docência, impactarão na profissão de professor de Geografia e na qualidade no seu ensino nas escolas brasileiras de modo geral.

No que se refere às questões das mudanças curriculares, o texto estabelece, ainda, que o currículo para o Ensino Médio se estruturará em duas partes. A primeira, obrigatória para todos os estudantes, e a segunda, dividida nos chamados itinerários formativos, que se estruturam em linguagens e suas tecnologias; matemática e suas tecnologias; ciências naturais e suas tecnologias; ciências humanas e sociais aplicadas; formação técnica e profissional. Enfatiza, também, que $60 \%$ da matriz curricular serão compostos de disciplinas obrigatórias e 40\%, de disciplinas optativas. Assim, no meio do curso, o estudante deverá escolher uma das áreas para se especializar. Quanto ao estudo de uma segunda língua estrangeira, fica facultado aos sistemas de ensino oferecê-lo. Saberes como Filosofia, Sociologia, Artes e Educação Física estão incluídos como temas transversais ou objeto de estudo dentro de outras disciplinas específicas, portanto, não são incluídos como disciplinas. No caso específico de Educação Física, a prática será facultativa. História e Geografia não são mencionadas no texto como saberes obrigatórios.

O texto ainda define que caberá à Base Nacional Curricular Comum (BNCC) do Ensino Médio definir quais conhecimentos devem ser ensinados em todo o país aos alunos dessa etapa escolar (BRASIL, Lei 13.415, 2017). A BNCC foi aprovada em 2018 e tem servido para estruturar a composição curricular dos Estados, Distrito Federal e municípios de médio e grande portes. No conjunto, tais medidas correspondem ao que os proponentes definem como flexibilização do currículo, cujo objetivo, segundo os mesmos, é o de possibilitar aos nossos jovens despertar o interesse por essa etapa de escolaridade e optar pelos conteúdos que queiram estudar.

Para Frigotto (2016b), a ideia dos estudantes optarem pelo que querem estudar é "uma traição aos alunos filhos dos trabalhadores, ao achar que deixando que eles escolham parte do currículo vai ajudá-los na vida. Um abominável descompromisso geracional e um cinismo covarde".

De antemão, aceitamos que precisamos enfrentar a baixa qualidade da formação dos nossos jovens nessa etapa de ensino. Entretanto, não concordamos que isso deve ser feito por meio de uma reforma imposta por medida provisória, forma bastante comum em regimes autoritários, e sem amplo debate com a sociedade, os profissionais que fazem a educação, as famílias e os alunos, estes últimos os mais interessados nessa questão. Aliás, em um governo estabelecido através de um golpe, com o objetivo de impor à classe trabalhadora as reformas de um projeto de gestão rejeitado, pela população, nas urnas, os encaminhamentos não poderiam ser diferentes. 
Amparando-nos em Frigotto (2016a), concordamos com a sua ideia de que "Apela-se para o interesse dos jovens como argumento, mas sem qualquer discussão com educadores, famílias e com os próprios estudantes sobre o significado da suposta falta de interesse e suas possíveis soluções”. Não é difícil entender que essa reforma trará grandes prejuízos à formação dos jovens brasileiros, especialmente a dos filhos da classe trabalhadora.

Para Frigotto (2016a), o conteúdo das mudanças no Ensino Médio “prioriza uma formação mínima, dual e desigual”. A prioridade por uma formação mínima pode ser notada, de acordo com a Lei 13.415/2017, em seu artigo 35-A, parágrafo $5^{0}$, no qual fica explícito que "a carga horária destinada ao cumprimento da Base Nacional Comum Curricular não poderá ser superior a mil horas do total da carga horária do ensino médio, de acordo com a definição dos sistemas de ensino" (BRASIL, Lei 13.415, 2017).

Assim, disponibiliza-se menos da metade do tempo da formação nessa etapa de escolaridade para os saberes clássicos. Os prejuízos para a formação não param nisso. Conforme Frigotto (op. cit.), a escolha dos itinerários formativos, a exemplo do itinerário em ciências da natureza ou a formação técnico-profissional, pode fazer com que o estudante nunca mais em sua vida tenha acesso a conhecimentos das áreas das ciências humanas e sociais e, por isso, ter sua leitura de mundo fortemente comprometida. Isso, segundo ele, converge totalmente com o Projeto Escola sem Partido e, em conjunto, visa a transformar os jovens brasileiros dessa geração em "analfabetos sociais". Mesmo que o estudante possa optar por cursar mais de um itinerário formativo, conforme prevê o artigo 36 , parágrafo $5^{0}$, da referida Lei, isso está condicionado à disponibilidade de vagas na rede. $\mathrm{Na}$ verdade, esta condição depende da capacidade de estrutura e de corpo docente, o que está longe de ser a realidade das escolas públicas, mas é plenamente possível nas grandes escolas privadas. Isso reforça o fosso de formação entre os jovens da classe trabalhadora e os demais dos outros estratos sociais.

Por outro lado, para Castilho (2017), ao contrário do que o governo divulga, os itinerários formativos não serão necessariamente escolhidos pelo aluno. Serão contemplados conforme as condições da escola em ofertá-los. Defende a premissa de que a escolha é um engodo, uma ficção, notadamente nas escolas públicas, cujo déficit histórico e estrutural é recorrente. Concordamos com o referido autor e acrescentamos que esse problema será muito maior nas escolas públicas dos municípios do imenso interior do Brasil, cuja estrutura material e de pessoal é ainda mais precária.

Não é difícil deduzir que tudo isso corrobora para que a reforma do Ensino Médio imprima uma dualidade à educação dos jovens brasileiros. De um lado, a preparação para o trabalho dos filhos 
dos trabalhadores, por meio da formação técnica-profissionalizante, que corresponde ao público a quem se destina esse tipo de instrução, nas redes públicas. De outro, uma formação completa e ilustrada, com conteúdos clássicos, para os filhos das elites. Isso, segundo Roberto Jamil Cury, especialista em legislação educacional, em matéria sobre a supracitada reforma, publicada pelo El País Brasil, em 2016, "vai confirmar algo que na história educacional do Brasil é muito recorrente, que é o que chamamos de dupla rede, a do homo sapiens e homo faber". Esclarece ainda que "A LDB, que define e regulariza a organização da educação brasileira, diz que o Ensino Médio é responsável pela formação completa do cidadão". No entanto, “Agora, [com essas mudanças] você está cortando a maçã pelo meio, entre quem terá formação operária e quem terá formação intelectual”.

Para Frigotto (2016b), isso retrocede ao obscurantismo de autores como Desttut de Tracy, que defendia, ao final do século XIX, ser da própria natureza e, portanto, independente da vontade dos homens, a existência de uma escola rica em conhecimento, cultura etc., para os que tinham tempo de estudar e se destinavam a dirigir no futuro, e outra escola rápida, pragmática, para os que não tinham muito tempo para ficar na escola e se destinavam (por natureza) ao duro ofício do trabalho.

Assim, promove-se o "fatiamento do ensino médio, com violenta redução de suas finalidades e da formação que deveria ser básica, unitária e comum a todos os estudantes". Com isso, "liquida a dura conquista do ensino médio como educação básica universal para a grande maioria de jovens e adultos, cerca de $85 \%$ dos que frequentam a escola pública". Por isso, representa "Uma agressão frontal à Constituição de 1988 e à Lei de Diretrizes da Educação Nacional que garantem a universalidade do ensino médio como etapa final de educação básica”. (FRIGOTO, 2016a)

A reforma do Ensino Médio, ao se caracterizar como minimalista e dual, também se constitui como desigual. "Ela camufla o fato de que para a maioria da classe trabalhadora o destino serão as carreiras de menor prestígio social e econômico". Além disso, por disponibilizar o mínimo dos conteúdos clássicos e destinar a formação técnica-profissional aos jovens pobres, levanta uma barreira imensa para o acesso dos mesmos às universidades públicas. Assim sendo, o caráter desigual da reforma acentua as já históricas desigualdades sociais do nosso país. Por isso, corresponde "a uma reforma que legaliza o apartheid social na educação no Brasil” (FRIGOTTO, 2016b).

Fica explícito que essa reforma, concretizada na Lei 13.415/2017, constitui-se como um dos capítulos da guinada neoliberal mais profunda do Estado brasileiro após os eventos políticos de 2016. Resta-nos, portanto, esboçar como ela expressa os postulados neoliberais na educação nacional. 


\section{OS POSTULADOS NEOLIBERAIS DA REFORMA}

Para Chauí (2016, p. 16), com o neoliberalismo o núcleo da privatização também está em outro lugar, está na transformação de um direito social em serviço que se compra e vende no mercado. Por isso, os postulados neoliberais advogam que a educação não se constitui como direito necessário ao aperfeiçoamento humano, mas um serviço a ser ofertado pelo mercado e sujeito ao seu controle e regulação.

Os problemas que se identificam como causadores da crise dos sistemas educacionais na atualidade são vistos como integrantes da própria crise que perpassa a forma de regulação assumida pelo Estado. Dai, concebe-se que a política educacional, tal como outras políticas sociais, será bem sucedida, na medida em que tenha por orientação principal os ditames e as leis que regem os mercados, o privado. Por isso, apregoa-se a necessidade de outro tratamento para o sistema educacional, a transferência ou divisão de responsabilidades administrativas com o setor privado, considerado como um meio de estimular a competição e o aquecimento do mercado, mantendo-se o padrão de qualidade na oferta do serviço. (AZEVEDO, 1997, p. 17)

Segundo Bianchetti (1996, p. 93), para analisar a orientação das políticas educacionais dentro do modelo neoliberal devemos considerar dois aspectos: os das tendências teóricas coincidentes com essa concepção social e que tem relação com a proposta de objetivos a serem alcançados pelo sistema educativo no que se refere à formação e capacitação de pessoas (estrutura e conteúdo dos currículos); os das políticas “para a educação" desenvolvidas pelo governo como parte das políticas sociais, que se refletem nas características e funções propostas para o sistema educativo. No geral, as ações se orientam fundamentalmente à conformação de uma estrutura educacional que seja o veículo de efetivação das exigências do modelo social.

Em outras palavras, a educação ocupa uma posição estratégica no projeto de hegemonia neoliberal, seja para atender aos propósitos empresariais (setor lucrativo de serviços) e industriais (formação de mão de obra), seja como um campo para a regulação e controle social. Silva (1994) é enfático, ao afirmar que a educação nos moldes neoliberais é direcionada à preparação para o trabalho (preparação dos alunos para a competitividade nacional e internacional) e à transmissão dos ideais que proclamam as excelências do livre mercado e da livre iniciativa. Por isso, deve estimular o empreendedorismo, a competição, o mérito, a individualização etc.

Nesse desiderato, é função dos sistemas educacionais formarem o "cidadão produtivo - o trabalhador que faz, produz mais rapidamente, tem qualidade ou é mais competente". (FRIGOTTO 
\& CIAVATTA, 2003, p. 50). Tal cidadão deve ser adaptado e preparado para responder, com eficiência e de maneira eficaz, às exigências do mercado. A formação desse cidadão produtivo é contraria a do cidadão capaz do exercício político crítico. Assim sendo, "A instituição escolar associada ao mercado rebaixa a educação ao comércio de mercadorias. Rebaixa as pessoas a produtores e consumidores que devem apenas encaixar-se em um mercado". (TIBURI, 2016)

Para formar o cidadão produtivo, a estrutura e os conteúdos dos currículos se fundamentam em tendências pedagógicas amparadas em filosofias pragmáticas ou em conceitos tributários de outros campos do saber, a exemplo do conceito de capital humano (a educação é o principal capital humano enquanto produtora de capacidade de trabalho, potenciadora do fator trabalho), forjado por Teodoro Schultz, da Escola Neoliberal de Chicago, mas que servem de suporte teórico à educação nos parâmetros do neoliberalismo. Por isso, a retomada de modelos pedagógicos tecnicistas coincidentes com essa concepção social. Com eles, instauram-se a lógica do cálculo custo/benefício na educação, os modelos de gestão das escolas inspirados em empresas, as parcerias público-privadas na gestão dos sistemas de ensino ou de escolas, os sistemas padronizados e unificados de avaliações externas, a valorização do método em detrimento do conteúdo, o ensino por habilidades e competências, o aprender a aprender, o controle sobre o trabalho docente, entre outros.

Em síntese, ainda em concordância com Silva (1994), há um esforço de alteração do currículo não apenas com o objetivo de dirigi-lo a uma preparação estrita para o local de trabalho, mas também com o objetivo de preparar os estudantes para aceitar os postulados do credo liberal.

Para se alcançar tudo isso, busca-se interditar as propostas curriculares que se fundamentam em tendências pedagógicas baseadas na filosofia da práxis, portanto, de caráter libertador, históricocrítica ou crítico social dos conteúdos.

No que se refere às disciplinas curriculares obrigatórias, a reforma do Ensino Médio, atendendo aos auspícios do neoliberalismo, tal qual estabelece a Lei 13.415/2017, elegeu Português e Matemática, além do ensino de rudimentos de lógica. Por outro lado, estabelece que todas as demais matérias passam a ser optativas e menos importantes para o projeto de sociedade que se inspira em suas doutrinas. Dentro dessa lógica, valorizam-se as matérias escolares que atendem melhor os objetivos e fins propostos e se relegam as que podem incitar a criticidade dos alunos, como as Ciências Humanas e suas possibilidades de construir o pensamento político crítico entre os jovens, a exemplo da Geografia. Assim sendo, resta-nos refletir sobre os prejuízos dessa lei para a formação integral, universal e omnilateral desses jovens, notadamente os filhos dos que vivem do trabalho, lançando nossas lentes para o caso da retirada da Geografia como disciplina obrigatória nessa etapa do ensino. 


\section{PARA ONDE VAI A GEOGRAFIA COM A REFORMA?}

É tese comum, ao menos entre os pensadores críticos da educação, que a chamada reforma do Ensino Médio desmancha ou destrói as possibilidades de uma formação integral, universal e omnilateral que possibilite aos estudantes uma leitura crítica e transformadora do mundo. Na nossa condição de geógrafo educador, compartilhamos o mesmo ponto de vista. Nossas preocupações não são casuais e tampouco ilações destituídas de fundamentos, mas baseadas em uma evidência explícita: no texto da Lei 13.415/2017, está ausente a obrigatoriedade da Geografia no currículo dessa etapa escolar. Como já salientado anteriormente, pelo que dispõem os parágrafos $3^{0}$ e $4^{0}$ do artigo 35 -A da referida Lei, apenas Matemática e Língua portuguesa se constituem como matérias obrigatórias nos três anos dessa etapa de escolarização. Matérias como História e Geografia não logram do mesmo prestígio. As duas fazem parte do itinerário formativo Ciências Humanas e Sociais Aplicadas, e, nele, a referida Lei não deixa claro se isso será como disciplinas ou conteúdos transversais.

Os esclarecimentos da então secretária executiva do MEC, Maria Helena Guimarães Costa, publicados em matéria do Jornal O Globo online, diante dos questionamentos de historiadores e geógrafos após a tramitação, a aprovação, a sanção e a publicação da MP 746/2016 como a Lei 13. 415/2017, não foram muito animadores para os que entendem a importância dessas matérias no Ensino Médio. Segundo a referida secretária, a BNCC do Ensino Médio, que definirá os conteúdos que devem ser ensinados nessa etapa, não trará disciplinas, a ideia de disciplinas está em desuso no mundo, as competências são transversais e tudo é uma mera questão de nomenclatura. As palavras da referida secretária só reafirmam duas grandes preocupações no que toca à Geografia: a sua supressão como disciplina obrigatória e necessária à formação dos jovens brasileiros e a dissolução da carreira do geógrafo.

A importância do saber geográfico para os homens já era salientada por Estrabão, na antiguidade, quando afirmou que quem o cultivava se preocupava com questões relativas à vida e à felicidade. Se quisermos reafirmar essa importância em tempos mais próximos da nossa era, desde Kant, pelo menos, o tempo e o espaço já eram considerados como fundamentais para a compreensão racional da experiência humana sobre a Terra. No campo da educação, um pensador do quilate de Paulo Freire enfatizou exaustivamente a dialética entre a palavra e o mundo, como condição para que a primeira tivesse sentido e o segundo fosse explicado pelos sujeitos do processo ensino/aprendizagem. Mesmo os adeptos das chamadas teorias pós-críticas advogam a grande relevância do espaço para a compreensão da contemporaneidade, a exemplo de Michel Foucault, 
quando salientou que os esquemas de explicação da modernidade deram primazia ao tempo e caberia esse papel ao espaço na era pós-moderna atual.

Esses exemplos nos ajudam a reafirmar que tanto a História quanto a Geografia permitem exercícios de reflexão que são fundamentais no Ensino Médio, etapa escolar que marca o amadurecimento dos estudantes. Por isso, sem essas reflexões teremos uma formação empobrecedora dos nossos jovens, especialmente daqueles que não terão garantidos os direitos a essas reflexões: os filhos dos trabalhadores brasileiros.

No que se refere à Geografia, esta se preocupa em explicar as complexas, diversas e multiescalares relações entre a sociedade e a natureza à luz do espaço geográfico. Trata da produção e reprodução social e histórica do espaço. Preocupa-se com as sociedades humanas em sua espacialidade. Por isso, pode fornecer importantes explicações para situar os filhos dos que vivem do trabalho no mundo. Pode, muito mais que isso, instrumentalizá-los para que, através da leitura crítica do mundo, possam transformá-lo.

A construção do sentido do mundo pelos jovens da classe trabalhadora tem como lugar privilegiado, embora não de forma exclusiva, as ciências humanas e, nelas, a Geografia tem muito a contribuir para que ela se realize, por meio da leitura consciente e crítica do seu objeto de estudo: o espaço geográfico. Por outro lado, para que esses jovens possam fazer essa leitura é preciso dotá-los do domínio de alguns procedimentos metodológicos que são próprios da ciência geográfica: observar, descrever, sintetizar, comparar, explicar, compreender e dominar os fundamentos teóricos e as técnicas de elaboração das representações cartográficas. São esses procedimentos que podem assegurar a competência metodológica para que os mesmos leiam o espaço, reconheçam as diferenças das configurações territoriais dos lugares e regiões, entendam os arranjos políticos e culturais que definem as múltiplas territorialidades dos grupos humanos, e compreendam os movimentos sociais superficiais ou de fundo que dão conformação às paisagens.

Assim, as reflexões, os métodos e as técnicas da Geografia para elaborá-las são fundamentais para que os jovens advindos da classe trabalhadora se tornem capazes de tomar decisões e exercitem a cidadania em toda a sua plenitude e que, portanto, não sejam apenas "cidadãos mínimos, ou seja, “cidadãos produtivos", que correspondem ao tipo de cidadão a que visa formar a proposta de novo Ensino Médio. Dessa forma, o ensino da Geografia pode auxiliá-los a desenvolverem raciocínios que lhes instrumentalizem "para saber pensar o espaço e nele saber agir" (LACOSTE, 1997). Desenvolver essa sabedoria é fundamental para qualquer projeto educativo que se proponha a emancipar os filhos da classe trabalhadora. 
Sobre o papel da educação na formação de homens sábios, Perez (2001, p. 119) nos chama a atenção para seguinte fato:

(...) a nossa humanidade realiza-se não pelo conhecimento, mas pela sabedoria. Formar homens sábios (e não eruditos) deve ser o ideal da educação. A sabedoria constrói-se a partir da compreensão, e esta não se desenvolve somente a partir do ponto de vista intelectualracional. Uma educação comprometida com o desenvolvimento da humanidade é uma educação para a sabedoria - uma educação e uma escola voltadas para a construção de uma sociedade verdadeiramente democrática, portanto, inclusiva e compreensiva.

Uma formação escolar que possibilite os jovens da classe trabalhadora o saber pensar e agir sobre o espaço geográfico é parte imprescindível dessa sabedoria necessária para se construírem projetos sociais alternativos e inclusivos, já que o domínio do espaço é condição para as estratégias políticas, econômicas e culturais da classe social que vive do trabalho, em suas lutas diárias para participar das decisões que afetam as suas vidas, para manter suas estratégias produtivas de sobrevivência e para reproduzir suas manifestações culturais e, por conseguinte, sua identidade, nas cidades e nos campos do Brasil.

Assim sendo, um processo de escolarização que possibilite a construção de raciocínios geográficos, por esses jovens, tem muito a colaborar com o "educar para que todos tenham condições de se tornar governantes" (GRAMSCI, 2006), uma vez que pode contribuir para a formação de sujeitos críticos e participativos das/nas decisões que afetam seus contextos territoriais.

Em outras palavras, o espaço geográfico é produto, reflexo, meio e condição de reprodução social. É, acima de tudo, como enfatizou Santos (1997), instância do social, que contém as outras instâncias: social, econômica, política, cultural etc., e é, por elas, contido. Por isso, é fundamental para a compreensão da complexidade do social. Em função disso, revela a sociedade em suas contradições, desigualdades e injustiças. Portanto, as reflexões geográficas são fundamentais no Ensino Médio e negá-las aos jovens da classe trabalhadora é precarizar a sua formação política, é torná-los alheios ou distantes dos projetos que se propõem a promover a emancipação humana, é distanciá-los do exercício político que vise a edificar uma humanidade solidária, é inviabilizar a construção de projetos sociais alternativos.

Nesse contexto, com a proposta pragmática do novo Ensino Médio, conforme a Lei 13.415/2017, que se propõe a formar cidadãos produtivos entre os jovens filhos da classe trabalhadora, e, para isso, retira as reflexões geográficas do rol das disciplinas curriculares obrigatórias, corre-se o risco de negar a formação humanista desses jovens. 
Assim, o projeto do novo Ensino Médio comporta os fundamentos de uma educação voltada para a adaptação e para a preparação de sujeitos aptos a responder com eficiência e de maneira eficaz às exigências do mercado. A retirada da obrigatoriedade da Geografia nessa etapa escolar corresponde a uma das faces mais evidentes do projeto, que é a de desmantelar a formação básica e tolher o pensamento crítico, necessários em qualquer projeto de mudança, fundamental para qualquer utopia de ruptura com os parâmetros sociais do capitalismo vigente.

Nesses termos, como enfatiza Mészarós (2008, p. 27), "Limitar uma mudança educacional radical às margens corretivas interesseiras do capital significa abandonar de uma só vez, conscientemente ou não, o objetivo de uma transformação social qualitativa". Transformação essa que está longe dos interesses das elites econômicas que tomam os sistemas escolares como espaços de produção de sujeitos conformistas e preparados para servir às engrenagens do sistema produtor de mercadorias. Desse modo, ainda segundo o referido autor (op. cit., p, 27), "procurar margens de reforma sistêmica na própria estrutura do capital é uma contradição em termos”. Por isso, para ele, "é necessário romper com a lógica do capital se quisermos contemplar a criação de uma alternativa educacional significativamente diferente".

Sendo assim, essa proposta de reforma carrega em si uma intenção: a formação de sujeitos obedientes, adaptados, despolitizados, individualistas, incapazes de pensar em projetos sociais coletivos de mudança, verdadeiros "analfabetos sociais" (FRIGOTTO, 2016b). Propõe-se, com ela, a dar continuidade à máquina educacional que trabalha para a manutenção da produção social de “deficientes cívicos”, em termos políticos e culturais (SANTOS, 2002). Em síntese, é uma engenharia social que visa a operacionalizar, por meio da educação, a edificação dos sujeitos sociais que Tiburi (2016, p. 11), inspirada em Theodor Adorno, reconheceu existirem em pleno século XXI, ou seja, sujeitos de consciência dissociada, incapazes de estabelecer nexo entre a cultura [técnica] e as questões humanas.

Por fim, cabe esclarecer que em nenhum outro momento da história educacional brasileira se ousou preterir da Geografia como saber obrigatório para a formação integral da juventude. No Brasil, ao menos desde o Império, a Geografia sempre gozou da condição de disciplina obrigatória e os saberes por ela veiculados sempre foram considerados importantes na formação dos estudantes, em todas as etapas do ensino. Nem mesmo na reforma educacional do período ditatorial (Lei 5. 692/71), resultante dos acordos MEC/USAID, que objetivava ajustar a educação brasileira à ruptura perpetrada pelo golpe militar de 1964, os saberes geográficos deixaram de compor o currículo obrigatório do Ensino Médio, embora com carga horária reduzida, muitos professores amordaçados 
e objetivos voltados para o enaltecimento do nacionalismo patriótico tão necessário aos idealizadores da máxima que visava a rechaçar as correntes divergentes de pensamento ao "Brasil: ame-o ou deixeo”. Esses saberes continuaram obrigatórios na reforma da década de 1990 (Lei 9. 394/96), que já apontava para a guinada pragmática/tecnicista da educação nacional, objetivando enquadrá-la aos ditames do mercado, em um período de adoção das doutrinas neoliberais pelo Estado brasileiro.

Enfim, sem uma sólida formação humanista dos jovens brasileiros, especialmente dos advindos da classe trabalhadora, o que impõe a obrigatoriedade do ensino das ciências humanas e sociais, a exemplo da Geografia, a reforma educacional do Ensino Médio, pelo seu pragmatismo ideológico/filosófico, pela tentativa de interdição de uma ideologia de esquerda e de uma filosofia da práxis, sorrateiramente incorpora as ideias do projeto "Escola sem Partido", defendido por segmentos conservadores da sociedade brasileira e pelas bancadas da bíblia, do boi e da bala no Congresso Nacional.

Fica explícito, também, que tudo isso impactará negativamente na carreira do geógrafo, acenando com a sua destruição e dissolução. A licenciatura em Geografia, em que pese à oferta do bacharelado nessa área, é quem tem permitido, indiscutivelmente, maior alcance dos egressos ao mercado de trabalho. Este fato acompanha essa disciplina desde a sua institucionalização, na Alemanha, no século XIX, quando os cursos de graduação nessa disciplina foram criados para formar os professores e atender às demandas dos sistemas escolares, conforme destaca Castilho (2017). Esse exemplo foi seguido por outros países centrais, como a Inglaterra e a França, mas também pelo Brasil, quando, especialmente a partir da década de 1930, em função do projeto de construção da identidade nacional do jovem brasileiro pelos sistemas escolares, essa disciplina ganhou relevo e foram criados os primeiros cursos objetivando formar os professores para o seu magistério.

A partir de então um fato ficou evidenciado: a grande demanda por profissionais da Geografia vem das escolas. Desobrigá-la na formação dos nossos jovens, como aponta a Lei 13.415/2017 que instaurou o novo Ensino Médio, é promover a retração da demanda por esses profissionais, o que coloca em questão o futuro dos mesmos e da licenciatura nesse campo do saber. Sem a sua obrigatoriedade, é evidente que o espaço de atuação do professor de Geografia, assim como a sua formação, se restringe. Por outro lado, essa restrição poderá acontecer com a abertura do seu magistério aos profissionais de notório saber (os seus bacharéis ou de outras disciplinas das humanidades), recrudescendo uma condição histórica que já acontece em seu ensino. Assim sendo, as duas alternativas apontam para a destruição ou dissolução da carreira do geógrafo educador. 
Ademais, se entendermos que a função da Geografia é possibilitar a leitura crítica, consciente e transformadora do mundo pelos jovens da classe trabalhadora e que estudam nas escolas públicas do Brasil, não podemos desconsiderar as ideias de Castilho (2017) quando chama a nossa atenção para que essa situação sirva de reconhecimento sobre a situação da educação e da formação do professor. Que sirva para revermos o modo como discutimos o ensino e como a escola real aparece em nossos debates. No que toca à questão do ensino de Geografia e da formação do seu professor na licenciatura, isso se torna ainda mais necessário e urgente.

Não é nenhum exagero admitir a persistência de uma metodologia fragmentada, informativa, generalista, descontextualizada, mnemônica, amparada no livro didático e que pouco contribui para a construção do raciocínio espacial ou da reflexão geográfica do mundo, pelas crianças e pelos jovens brasileiros, no ensino da disciplina geográfica em todas as etapas de escolarização do Brasil, mesmo com a possibilidade de abordagens pedagógicas mais atualizadas e comprometidas com a formação política dos alunos.

Também não é exagero admitir que a formação do professor de Geografia parece contribuir, sobremaneira, para que isso continue acontecendo. A título de exemplos, podemos destacar: a persistência das velhas dualidades entre o físico e o humano, bem como entre os conceitos, as teorias, os conteúdos, a preparação didático-pedagógica e os estágios supervisionados, que são fundamentais para lecioná-la, apesar de muitas propostas curriculares que se propõem a superar o velho esquema formativo " $3+1$ "; a desvinculação das pesquisas com o ensino, pois as primeiras atendem muito mais ao que se espera do bacharel e pouco enfatizam a questão do ser professor e do ensinar essa disciplina; o descompromisso da maioria dos professores formadores com a formação para a docência, o que representa uma silenciosa bacharelarização da licenciatura, entre tantos que não se constituem em objetivos principais dessa reflexão.

Assim sendo, façamos da luta pela manutenção da obrigatoriedade da Geografia em todo o currículo da Educação Básica um motivo para discutirmos o seu ensino nas escolas e a formação do professor que preparamos para esse exercício. Para isso, deveremos deixar que as "nossas torres acadêmicas de marfim se transformem em escombros, em ruínas”. Precisaremos abandonar as nossas "ilhas de produção" de nacos de saber que não referendam o ensino dessa matéria. Só assim superaremos nossa indignação como retórica, pois ela não esconde o individualismo e a competição que têm estruturado a nossa prática e inviabilizado a montagem de estratégias coletivas de ação, voltadas à construção de projetos sociais coletivos e alternativos, e que não podem prescindir da 
leitura crítica do espaço geográfico pelo estudante. Só assim evitaremos que o Estado ponha “a pá de cal" definitiva no futuro de uma disciplina moribunda nos sistemas escolares.

\section{CONSIDERAÇÕES FINAIS}

O novo Ensino Médio corresponde a mais uma das reformas conservadoras impostas, pelo governo de Michel Temer, à sociedade e, principalmente, aos trabalhadores brasileiros. As mudanças mais evidenciadas para essa etapa de ensino, conforme a Lei 13.415, são as relativas à carga horária, à configuração curricular, com a desobrigação das ciências humanas, entre ela a Geografia, e à formação do professor, nesse último caso com a permissão para que pessoas, sem a preparação para o magistério, mas como notório saber, possam atuar no campo educacional nessa etapa, com todas as implicações que isso pode trazer para a profissionalização docente.

Tudo isso corrobora para que a mesma possa ser definida como um conjunto de mudanças que faz a educação nacional retroceder aos mais baixos níveis de qualificação. Assim, constitui-se como uma reforma "mínima, dual e desigual" (FRIGOTTO, 2016b), porque não garante uma formação integral, universal e omnilateral aos filhos dos trabalhadores brasileiros e, por isso, constitui-se como um ataque frontal ao que estabelecem a Constituição de 1988 e a LBD de 1996, pondo os objetivos do PNE em risco.

Nessa conjuntura, a Geografia não aparece como disciplina obrigatória, o que trará grandes prejuízos para a formação dos jovens da classe trabalhadora brasileira, que não terão as possibilidades de dispor da leitura consciente, crítica e transformadora do mundo à luz do espaço geográfico e nem dominarão os procedimentos metodológicos dessa ciência e que são fundamentais para a realização dessa leitura. Por outro lado, a desobrigação da Geografia e a abertura para o exercício do seu magistério por profissionais de notório saber impactarão na formação e provocarão a redução da demanda pelo trabalho do geógrafo nas escolas dessa etapa de ensino.

Por fim, o projeto novo Ensino Médio corresponde a uma reforma que destrói as possibilidades de formação integral dos jovens pobres brasileiros e, por isso, torna-lhes impossibilitados de construir uma leitura política do mundo que lhes ajudem a superar o atual estado de coisas que os exclui. Pelo seu pragmatismo pedagógico, que atende ao contexto neoliberal atual, no qual a educação é tida como serviço e a escola como o espaço de formação de consumidores e produtores, essa reforma acena com o triunfo da razão instrumental sobre o pensamento humanista, dai, carrega em si uma intenção: a formação de sujeitos obedientes, adaptados, despolitizados, 
individualistas, incapazes de pensar em projetos sociais coletivos de mudança, verdadeiros "analfabetos sociais" (FRIGOTTO, 2016b). Assim sendo, constitui-se como uma máquina educacional que trabalha para a manutenção da produção social de "deficientes cívicos", em termos políticos e culturais (SANTOS, 2002). Em suma, operacionaliza, por meio da educação, a edificação dos sujeitos sociais que Tiburi (2016, p. 11), inspirada em Theodor Adorno, reconheceu existirem em pleno século XXI, ou seja, sujeitos de consciência dissociada, incapazes de estabelecer nexo entre a cultura [técnica] e as questões humanas.

\section{REFERÊNCIAS}

AZEVEDO, J. M. L. A educação como política pública. Campinas-SP: Autores Associados, 1997.

BIANCHETTI, R. G. Modelo neoliberal e políticas educacionais. 2. ed. São Paulo: Cortez, 1996.

BRASIL. Lei n. 13.415, de fevereiro de 2017. Presidência da República. Casa Civil. Subchefia para Assuntos Jurídicos. Disponível em http//www.planalto.gov.br. Acesso em 01 de junho de 2017.

CASTILHO, D. Reforma do Ensino Médio: desmonte na educação e inércia do enfrentamento retórico. In: Pragmatismo Político. Disponível em https://www.pragmatismopolitico.com.br. Acesso em 28 de maio de 2017.

CHAUÍ, M. Sociedade brasileira: autoritarismo por todos os lados. Entrevista. In: Revista Cult, ano 19, n. 209, Fevereiro/2016.

FRIGOTTO, Gaudêncio. Entrevista. In: Portal de Periódicos da Fiocruz. 2016a. Disponível em periódicos.fiocruz.br/pt/gov/gaudencio-frigotto. Acesso em 01 de Junho de 2017.

. Reforma de ensino médio do (des)governo de turno: decreta-se uma escola para os ricos e outra para os pobres. 2016b. Disponível em www.anped.org.br. Acesso 01 de junho de 2017.

FRIGOTTO, G \& CIAVATTA, M. Educar o trabalhador produtivo ou o ser humano emancipado? In: Trabalho, Educação e Saúde, 1(1); 45-60 p, 2003.

GRAMSCI, A. Cadernos do Cárcere. Volume 2. Tradução de Carlos Nelson Continho. 4. ed. Rio de Janeiro: Civilização Brasileira, 2006.

LACOSTE, Y. A geografia isso serve, em primeiro lugar, para fazer a guerr $a$. Tradução de Maria Cecília França. 4. ed. Campinas: Papirus, 1997.

MÉSZÁROS, I. Educação para além do capital. 2. ed. São Paulo: Boitempo, 2008. (Mundo do trabalho).

PAINS, C; ALVIM, M. \& MARIZ, R. Ausência de História e Geografia no novo ensino médio gera apreensão. In: O globo. Disponível em https://oglobo.globo.com. Acesso em 01 de maio de 2017. 
PEREZ, C. L. V. Leituras de mundo/leituras de espaço: um diálogo entre Paulo Freire e Milton Santos. In: GARCIA, R. L (org.). Novos olhares sobre a alfabetização. São Paulo: Cortez. 2001.

ROSSI, M. Reforma do Ensino Médio é aprovada no Senado. In: El País Brasil. Disponível em https://brasil.elpais.com. Acesso em 01 de maio de 2017.

SANTOS, M. Metamorfoses do espaço habitado. São Paulo: Hucitec, 1997.

A natureza do espaço: técnica e tempo, razão e emoção. São Paulo: Hucitec, 1999. . O país distorcido. São Paulo: Publifolha, 2002.

SAVIANI, D. História das Ideias Pedagógicas no Brasil. 4. ed. Campinas-SP: Autores Associados, 2013. (Coleção Memória da Educação).

SILVA, T. T. Neoliberalismo, Qualidade Total e Educação. Petrópolis: Vozes, 1994.

TIBURI, M. Educação meia-boca. Sobre a dissociação da consciência. In: Revista Cult, ano 19, n. 219, dez./2016. 